\title{
TyPe 2 DiABETES MELlitus IS ASSOCIATED WITH CAROTID ARTERY PLAQUES IN PATIENTS WITH PREMATURE CORONARY HEART DISEASE
}

\author{
J. Gabriel Juárez-Rojas ${ }^{1}$, Carlos Posadas-Romero ${ }^{1}$, Rocío Martínez-Alvarado ${ }^{1}$, \\ Esteban Jorge-Galarza ${ }^{1}$, JuAn Reyes-BARRera ${ }^{1}$, L. Gabriela SÁNCHEZ-LOZAdA ${ }^{2}$, \\ Margarita Torres-TamaYo ${ }^{2}$ and AIDA X. Medina-Urrutia ${ }^{2 *}$ \\ ${ }^{1}$ Department of Endocrinology; ${ }^{2}$ Department of Nephrology, Laboratory of Renal Physiopathology. \\ Instituto Nacional de Cardiología Ignacio Chávez, Mexico City, Mexico
}

\begin{abstract}
Background: In subjects without a history of coronary heart disease (CHD), type 2 diabetes mellitus (T2DM) is associated with carotid artery plaques (CAP), which is a better marker than high carotid intima-media thickness (hCIMT) for predicting first or recurrent cardiovascular events. Objective: The objective of this study is to analyze the association of T2DM with CAP and hCIMT in premature CHD patients. Methods: Premature CHD was considered before the age of 55 years in men and before 65 in women. T2DM was defined according to the American Diabetes Association criteria. CAP was defined as a focal structure encroaching the arterial lumen by at least $50 \%$ of the surrounding IMT value or with a thickness > $1.5 \mathrm{~mm}$. Results: Among 1196 patients (CHD duration 1.5 years [interquartile range: 0.4-5.6]), 37.2\% had T2DM, and $97.8 \%$ were on antihypertensive, $94.4 \%$ on lipid-lowering, and $97.3 \%$ on anti-aggregate treatment. hCIMT prevalence was similar in patients with or without T2DM, whereas CAP prevalence was higher among T2DM patients (17.7\% vs. $30.9 \% ; p<0.001$ ). T2DM showed association with CAP, independently of CHD evolution and glycemic control (odds ratio: 1.57 ; $95 \%$ confidence interval: $1.09-2.26$ ). Conclusions: T2DM has an independent association with CAP. Early detection of recurrent cardiovascular events, with CAP identification, could be useful to prevent complications in patients with CHD. (REV INVEST CLIN. 2018;70:301-9)
\end{abstract}

Key words: Coronary heart disease. Atherosclerosis. Carotid intima-media thickness. Carotid artery plaques. Diabetes mellitus.

Corresponding author:

*Aida X. Medina-Urrutia

Juan Badiano, 1

Col. Sección XVI, Del. Tlalpan

C.P. 14080, Mexico City, Mexico

Received for publication: 15-05-2018

E-mail: aidaxm@yahoo.com

Approved for publication: 25-06-2018 doi: $10.24875 / R I C .18002591$ 


\section{INTRODUCTION}

Atherosclerosis is a systemic chronic inflammatory disorder involving multiple vascular territories ${ }^{1,2}$. High carotid intima-media thickness (hCIMT) is considered a marker of atherosclerosis in the vascular beds of the human body ${ }^{3,4}$. However, mean and maximal CIMT measurements have been controversially associated with cardiovascular risk ${ }^{5}$, whereas carotid artery plaques (CAP) are closely related to the presence of coronary artery plaques ${ }^{1,2}$. Moreover, it has been reported that the presence of carotid plaques is better than $\mathrm{hCIMT}$ to predict coronary heart disease $(\mathrm{CHD})^{6-9}$, as well as major cardiovascular events and mortality in patients with established $\mathrm{CHD}^{10}$.

Type 2 diabetes mellitus (T2DM) is increasing worldwide ${ }^{11,12}$. Macrovascular complications of T2DM are frequent causes of morbidity and mortality, and some investigations have reported that, compared to non-diabetic subjects, CHD is higher among patients with diabetes, independently of cardiovascular risk factors ${ }^{13,14}$. In addition, some reports have suggested that $65-80 \%$ of deaths from T2DM are due to cardiovascular or cerebrovascular complications ${ }^{15}$.

Few studies have investigated the association of T2DM with the presence of CAP in subjects without apparent cardiovascular disease. Those reports showed that CAPs are useful for predicting the presence and extent of CHD in patients with diabetes ${ }^{16,17}$. Although currently, it is well known that deaths in T2DM patients are mainly due to cardiovascular or cerebrovascular complications ${ }^{15}$. As far as we know, no study has analyzed the association of diabetes with CAP in patients with established premature coronary artery disease. The purpose of the present study was to evaluate the association of T2DM with CAP and hCIMT in an adult population with documented premature CHD. This is important because modern cardiovascular care includes the early detection of recurrent cardiovascular events, especially in patients with premature CHD, whose identification of risk through atherosclerotic markers, such as carotid plaques, could be useful in the prevention of morbidity and mortality, besides traditional risk factors.

\section{MATERIALS AND METHODS}

\section{Patient population}

The study population was recruited from patients participating in the Genetics of Atherosclerotic Disease (GEA) study. The GEA study is a cross-sectional and observational trial designed to examine the genomic basis of CHD and to assess the relationships of traditional and emerging risk factors with clinical and subclinical atherosclerotic vascular disease in an adult Mexican population ${ }^{18}$. Briefly, a convenience sample of 1200 premature CHD patients aged 35-74 years was recruited from the outpatient clinic of the $\mathrm{Na}$ tional Institute of Cardiology in Mexico City (July 2008-November 2012). Premature CHD was defined as a history of myocardial infarction, angioplasty, revascularization surgery, or coronary stenosis > 50\% by angiography, diagnosed before age 55 in men and before 65 in women. Coronary patients and control subjects with a personal history of renal, liver, thyroid, or malignant disease, as well as those on treatment with corticosteroids, were excluded from the study. The GEA study was approved by the the Institutional Ethics Committee on research in humans at the $\mathrm{Na}$ tional Institute of Cardiology and conducted according to the ethical guidelines of the 1975 Declaration of Helsinki. Written informed consent was obtained from each participant who was included in the study.

This study is a cross-sectional analysis of 1196 GEA patients because we excluded four patients with missing data. Trained research staff interviewed all subjects and completed questionnaires to collect information pertaining to demographic characteristics, CHD history, medication, and alcohol and tobacco use. Positive history of tobacco was considered when individuals self-reported current smoking ( $\geq 1$ cigarette per day $)^{19}$. Physical activity index was calculated using the Baecke questionnaire ${ }^{20}$, and total activity was obtained from the sum of work, sport, and leisure-time activities. This questionnaire has been previously validated in an adult population and provides reliable information. All participants had a complete clinical examination. Height was measured to the nearest $1 \mathrm{~cm}$ using a rigid stadiometer, and weight was measured to the nearest $0.1 \mathrm{~kg}$ with the use of a balance scale. Body mass index (BMI) was calculated as weight in kilograms divided by height in meters squared. Systolic and diastolic blood pressure was measured after 
subjects had rested for at least $10 \mathrm{~min}$, and the average of the second and third of three consecutive measurements was used for the analysis. Hypertension was defined as blood pressure $>140 / 90 \mathrm{mmHg}$ or treatment with antihypertensive medication.

\section{Biochemical analysis}

Venous blood samples were collected from subjects after a $10 \mathrm{~h}$ fasting. Plasma glucose, total cholesterol, high-density lipoprotein cholesterol (HDL-C), and triglycerides were measured in fresh samples, using standardized enzymatic procedures in a Hitachi 902 Analyzer (Hitachi LTD, Tokyo, Japan). Accuracy and precision of lipid measurements in our laboratory are under periodic surveillance by the center for disease control and prevention (Atlanta, GA, USA). Low-density lipoprotein cholesterol (LDL-C) was estimated using the De Long et al. method ${ }^{21}$. Hyperlipidemia was defined as total cholesterol $>200 \mathrm{mg} / \mathrm{dL}$ or triglycerides $>150 \mathrm{mg} / \mathrm{dL}$ or use of lipid-lowering medication. The presence of T2DM was considered when fasting plasma glucose was $\geq 126 \mathrm{mg} / \mathrm{dL}$, according to the American Diabetes Association criteria ${ }^{22}$, and when participants reported glucose-lowering treatment or a previous diagnosis by a physician. A $1 \mathrm{C}$ hemoglobin was measured by immunoassay method in a COBAS C 501 Clinical Chemistry Analyzer (Roche Diagnostics GmbH, Mannheim, Germany). As informed, for patients with micro- or macro-vascular complications, $\mathrm{A} 1 \mathrm{C}<8 \%$ was considered a good glycemic control ${ }^{22}$. Total highsensitivity C-reactive protein (hs-CRP) levels were determined by immunonephelometry on a BN Pro Spec nephelometer (Dade Behring, Marburg, Germany), according to the manufacturer's method. Interassay coefficients of variation for all assays were $<6 \%$.

\section{Computed tomography}

Computed tomography is a validated method for measuring adipose tissue distribution ${ }^{23}$. Computed tomography was performed using a 64-channel multidetector helical system (Somatom Cardiac Sensation 64, Forcheim, Germany) and interpreted by experienced radiologists. Scans were read to assess and quantify total, subcutaneous, and visceral abdominal adipose tissue, as described by Kvist et al. ${ }^{24}$. Twenty different scans were randomly selected to evaluate the consistency of interpretation; the intraobserver correlation coefficient was $0.99(p<0.001)$.

\section{Measurement of CIMT}

Carotid artery scanning was performed with a highresolution ultrasound apparatus in $\mathrm{B}$ mode (Sonosite Micro Maxx), equipped with a $13-6 \mathrm{MHz}$ linear array transducer. The subjects were assessed in supine position, with extended neck. Measurements of common CIMT were performed in 2-cm-long segments immediately proximal to the carotid bulb bifurcation. The distance between the arterial intima-lumen interface and the media-adventitia interface of the far wall quantified the thickness of the intima-media. Five measurements were performed in the right and left carotid arteries. The CIMT was defined as the average of all measurements. A high CIMT was defined using the $75^{\text {th }}$ percentile, according to age group and gen$\mathrm{der}^{25}$. If a carotid plaque was present, CIMT was measured in a contiguous segment without plaque. Carotid plaque was defined as a focal structure encroaching the arterial lumen by at least $50 \%$ of the surrounding IMT value or with a $>1.5 \mathrm{~mm}$ thickness ${ }^{25}$. The bilateral common carotid, internal carotid, and bulb were scanned to evaluate the presence of plaque. One, especially, trained radiologist, who was unaware of the studied subject's clinical and angiographic information, performed all ultrasonographic examinations. Reproducibility of measurements was assessed with $5 \%$ of the cohort, obtaining an intraobserver correlation coefficient of 0.96 .

\section{Data analysis}

Variables were analyzed in the whole sample, and participants were stratified by the presence or absence of T2DM. Values are expressed as mean \pm standard deviation, median (interquartile range), or number of subjects (\%). Comparisons of means medians, and frequencies were made with Student's t, MannWhitney $U$, and Chi-squared tests, respectively. Logistic regression analyses were done to evaluate the association of T2DM with carotid plaques, using hypoglycemic treatment, years of diabetes evolution, and CHD, as well as clinical or biochemical parameters that were different between subjects with or without T2DM, as independent variables. All analyses were carried out using the statistical software SPSS v. 15.0 (SPSS Chicago, II.). All $p<0.05$ or $95 \%$ confidence intervals $(95 \% \mathrm{Cl})$ that excluded the unit were considered statistically significant. 
Figure 1. Pharmacological treatment of patients with premature coronary artery disease $(n=1196){ }^{*}$ Only patients with type 2 diabetes mellitus $(n=445)$.

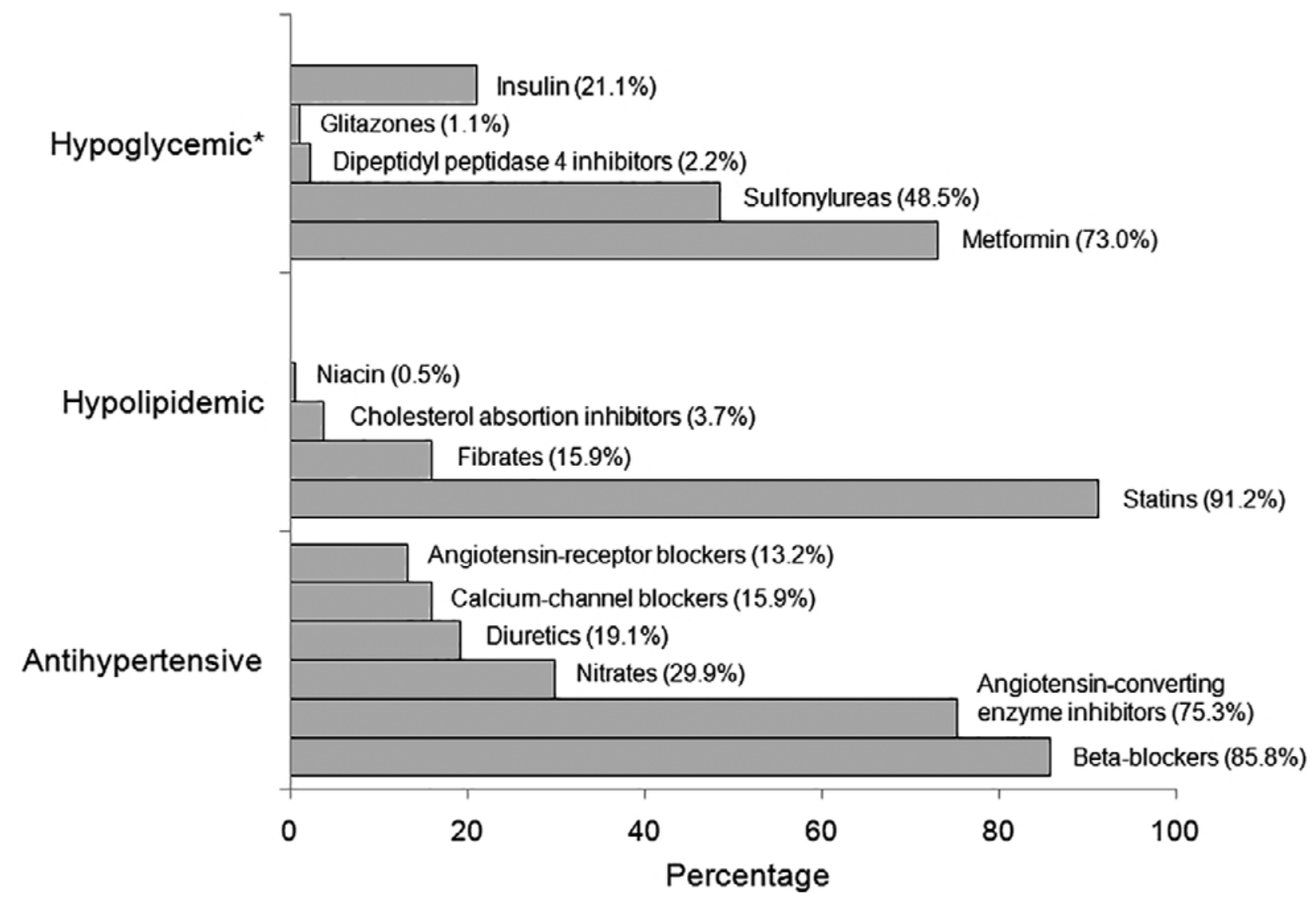

\section{RESULTS}

Among the 1196 patients from the GEA cohort (cardiovascular disease duration, 1.5 years [0.4-5.6]), $37.2 \%$ coursed with type 2 diabetes, $69.6 \%$ with hypertension, $20.8 \%$ with high total cholesterol levels, $56.3 \%$ with hypertriglyceridemia, and $97.8 \%$ were on antihypertensive, $94.4 \%$ on lipid-lowering, and $97.3 \%$ on anti-aggregate treatment (Fig. 1). Compared with non-diabetes patients, a higher prevalence of female sex $(26.5 \%$ vs. $15 \% ; p<0.001)$ and hypertension (78.0\% vs. $64.7 \%$; $p<0.001$ ) was found in diabetes subjects, as well as a lower index of total physical activity (7.5 [6.7-8.6] vs. 8.0 [6.99.4]; $p<0.001$ ). As shown in table 1 , diabetes patients were also characterized by having higher values in age, BMI, total and visceral adipose tissue, systolic blood pressure, triglycerides, glucose, and hs-CRP ( $p<0.05$, for all). LDL-C was significantly lower in diabetes patients, and there were no differences between the groups regarding cardiovascular disease duration, hyperlipidemia, pharmacological treatment, smoking status, subcutaneous adipose tissue, diastolic blood pressure, and HDL or non-HDL cholesterol.

Among the 445 patients with diabetes, $92.8 \%$ were on hypoglycemic treatment (Fig. 1). According to their A $1 \mathrm{C}$ hemoglobin, target was achieved in $58.2 \%$ of the patients with diabetes. This prevalence was inversely related with diabetes duration: < 1 year, $84.6 \%$; $1-5$ years, $77.2 \%$; $6-10$ years, $52.5 \%$; and $>10$ years, $37.8 \%$ ( $p$ trend $<0.001$ ). Except for stable angina prevalence, clinical characteristics of CHD were similar in patients with or without diabetes (Table 2). Although the prevalence of hCIMT was greater than that of CAP, the first was similar between groups, whereas carotid plaque prevalence was significantly higher among patients with diabetes (Fig. 2).

To know whether diabetes is independently associated with the presence of carotid plaques, a logistic 
Table 1. Demographic, adipose, and biochemical characteristics of patients with coronary heart disease.

\begin{tabular}{|c|c|c|c|c|}
\hline & $\begin{array}{c}\text { Total } \\
(\mathrm{n}=1196)\end{array}$ & $\begin{array}{c}\text { Diabetes }(-) \\
\quad(n=751)\end{array}$ & $\begin{array}{c}\text { Diabetes }(+) \\
\quad(n=445)\end{array}$ & $p^{*}$ \\
\hline Age (years) & $54 \pm 8$ & $53 \pm 8$ & $56 \pm 8$ & $<0.001$ \\
\hline Female sex (\%) & 19.3 & 15.0 & 26.5 & $<0.001$ \\
\hline Positive tobacco history (\%) & 11.7 & 12.5 & 10.3 & 0.257 \\
\hline Body mass index $\left(\mathrm{Kg} / \mathrm{m}^{2}\right)$ & $28.9 \pm 4.3$ & $28.7 \pm 4.1$ & $29.3 \pm 4.6$ & 0.030 \\
\hline Total adipose tissue $\left(\mathrm{cm}^{2}\right)$ & $429(340-531)$ & $421(335-519)$ & $444(358-554)$ & 0.001 \\
\hline Subcutaneous adipose tissue $\left(\mathrm{cm}^{2}\right)$ & $249(194-319)$ & $244(192-313)$ & $252(201-330)$ & 0.130 \\
\hline Visceral adipose tissue $\left(\mathrm{cm}^{2}\right)$ & $170(130-218)$ & $163(125-209)$ & $182(139-238)$ & $\leq 0.001$ \\
\hline Systolic blood pressure $(\mathrm{mmHg})$ & $119 \pm 19$ & $117 \pm 17$ & $123 \pm 21$ & $<0.001$ \\
\hline Diastolic blood pressure ( $\mathrm{mmHg}$ ) & $72 \pm 10$ & $72 \pm 10$ & $73 \pm 10$ & 0.223 \\
\hline Total cholesterol (mg/dL) & $166 \pm 48$ & $167 \pm 45$ & $165 \pm 51$ & 0.459 \\
\hline LDL-cholesterol (mg/dL) & $96 \pm 39$ & $98 \pm 39$ & $92 \pm 39$ & 0.015 \\
\hline Non-HDL-cholesterol (mg/dL) & $120(93-151)$ & $121(95-151)$ & $118(89-153)$ & 0.234 \\
\hline HDL-cholesterol (mg/dL) & $37(32-44)$ & $37(31-44)$ & $37(32-44)$ & 0.936 \\
\hline Triglycerides (mg/dL) & $162(118-220)$ & $160(116-212)$ & $166(124-231)$ & 0.026 \\
\hline Glucose (mg/dL) & $112 \pm 44$ & $91 \pm 10$ & $148 \pm 54$ & $<0.001$ \\
\hline hs C-reactive protein (mg/L) & $1.2(0.6-2.7)$ & $1.12(0.59-2.42)$ & $1.36(0.74-3.10)$ & 0.002 \\
\hline
\end{tabular}

Data are expressed as mean $\pm S D$, median (interquartile range) or percentage. ${ }^{*} p$ values comparing non-diabetes $(-$ ) versus diabetes $(+)$ patients by unpaired-t, Mann-Whitney U, or Chi-squared test, LDL: low- density lipoprotein, HDL: high-density lipoprotein and hs: high sensitivity.

Table 2. Cardiovascular diagnoses of patients with coronary heart disease.

\begin{tabular}{|c|c|c|c|c|}
\hline & $\begin{array}{c}\text { Total } \\
(\mathrm{n}=1196)\end{array}$ & $\begin{array}{l}\text { Diabetes }(-) \\
(n=751)\end{array}$ & $\begin{array}{l}\text { Diabetes }(+) \\
(n=445)\end{array}$ & $p^{*}$ \\
\hline $\begin{array}{l}\text { Coronary heart disease evolution } \\
\text { (years) }\end{array}$ & $1.50(0.40-5.60)$ & $1.53(0.41-5.58)$ & $1.44(0.46-5.56)$ & 0.985 \\
\hline Acute myocardial infarction (\%) & 88.5 & 88 & 89.2 & 0.531 \\
\hline Unstable angina (\%) & 15.3 & 16 & 14.2 & 0.401 \\
\hline Stable angina (\%) & 29.4 & 27.3 & 32.9 & 0.042 \\
\hline $\begin{array}{l}\text { Coronary percutaneous } \\
\text { intervention }(\%)\end{array}$ & 47.8 & 48.5 & 46.7 & 0.563 \\
\hline Stent (\%) & 45 & 45.2 & 44.7 & 0.853 \\
\hline Cardiac revascularization (\%) & 10 & 9.6 & 10.8 & 0.505 \\
\hline High CIMT (\%) & 46.5 & 44.2 & 47.7 & 0.316 \\
\hline
\end{tabular}

Data are expressed as median (interquartile range) or percentage. ${ }^{*} p$ values compared non-diabetes $(-)$ versus diabetes (+) patients by Mann-Whitney U or Chi-square test. CIMT: carotid intima-media thickness.

regression analysis was performed including therapy and clinical or biochemical characteristics as covariates. As shown in figure 3, age was associated with CAP (odds ratio [OR]: 1.10; $95 \%$ confidence interval [Cl]: 1.07-1.13), but it was lower than that observed for diabetes, which showed a stronger association with the presence of CAP (OR: $1.57 ; 95 \%$ Cl: 1.09-2.26). 
Figure 2. Carotid intima-media abnormalities in patients with premature coronary artery disease. Prevalence of high carotid intima-media thickness (hCIMT; according to age and sex) and carotid plaque presence in patients with premature coronary artery disease and absence $(-)$ or presence $(+)$ of type 2 diabetes mellitus. ${ }^{*}$ Chi-square test.

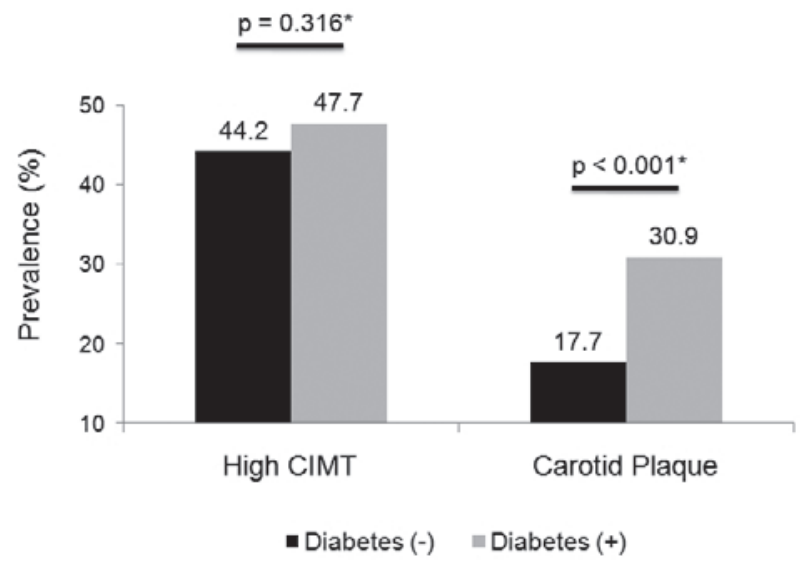

\section{DISCUSSION}

Patients with established $\mathrm{CHD}$ are at an increased risk of total and cardiovascular mortality ${ }^{26}$ and have been established as a top-priority group for prevention in clinical practice ${ }^{27}$. In this regard, some studies have suggested that, rather than CIMT, the presence of carotid artery plaque could strongly predict mortality and major cardiovascular events, even in patients with established $\mathrm{CHD}^{6-10}$. In line with this, results of the present study show that, compared with premature CHD patients without diabetes, those with T2DM have a more adverse cardiovascular risk profile, but it does not identify a higher prevalence of elevated CIMT. Moreover, our main finding indicates that T2DM has a strong association with the presence of CAP, independently of CHD evolution and glycemic control. This is relevant because the presence of CAP could be useful for the early detection of recurrent cardiovascular events and to promote prevention programs, which are the goals of modern cardiovascular care, especially in patients with established premature cardiovascular damage, whose accelerated progression of $\mathrm{CHD}$ is significant, regardless of their different clinical profile. In addition, these patients do not frequently have traditional CHD risk factors and are overlooked and misdiagnosed ${ }^{28,29}$.

Coronary artery disease remains the major cause of morbidity and mortality around the world. Currently,
Figure 3. Association of type 2 diabetes mellitus with carotid artery plaque presence in patients with premature coronary artery disease. Multiple logistic regression analysis was carried out in the whole studied population. Type 2 diabetes mellitus, age, sex, visceral adipose tissue, systolic blood pressure, low-density lipoprotein cholesterol, triglycerides, high-sensitivity C-reactive protein, physical activity, coronary heart disease, and type 2 diabetes mellitus years of evolution, as well as hypoglycemic treatment, were included as independent variables in the model.

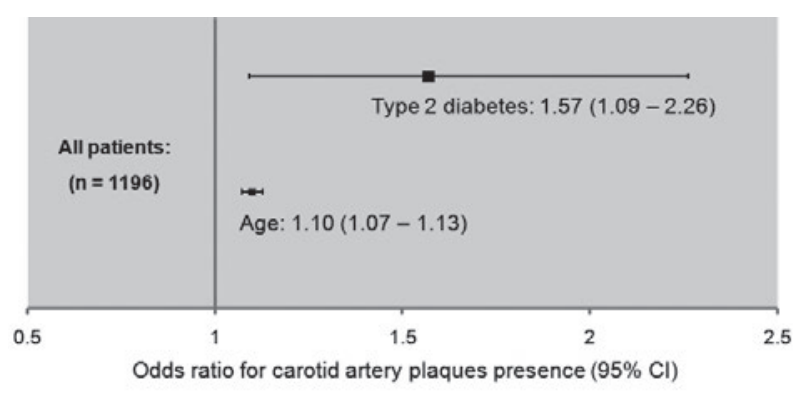

subjects within the age group of 40-60 years are more susceptible to CHD due to the current pandemic of metabolic disorders associated with obesity, such as hypertension, dyslipidemia, or diabetes ${ }^{30}$. Results of the present study, which include subjects with $\mathrm{CHD}$ diagnosed before age 55 in men and before 65 in women, show that compared to non-diabetes patients, those with diabetes were older and had higher general and central adiposity, hypertension, and carotid artery plaque prevalence. Similar to this, three previous studies that investigated mortality in cardiac patients showed a trend of high prevalence of CAP among patients with diabetes ${ }^{8,10,28}$. To be noted, only one of these studies ${ }^{10}$ showed a prevalence of CAP (36.4\%) similar to that observed in our diabetes cohort (23.1\%). The other two studies found carotid plaques in $75 \%-80 \%$ of the CHD patients with diabetes. These differences can be primarily explained by the differences in the ethnic group as well as the higher age and CHD evolution time, poor pharmacological treatment, or higher hypertension, dyslipidemia, and smoking prevalence in those studies 8,28 .

The two most widely used protocols for evaluating carotid abnormalities are the mean common and mean maximum intima-media thickness measurements ${ }^{5,31}$. Nevertheless, CAP presence has been shown to be more closely associated with incidence or recurrence of major cardiovascular events, in 
healthy or $\mathrm{CHD}$ subjects ${ }^{7-10}$. Results of the present study indicate that, although almost half (45.6\%) of the included CHD patients had elevated CIMT, there are no differences in the elevated CIMT prevalence between patients with and without diabetes mellitus. Moreover, the data show that, compared to CHD patients without diabetes, those with diabetes had almost twice the prevalence of CAP ( $17.7 \%$ vs. $30.9 \% ; p<0.001)$. This information suggests that patients with diabetes and presence of carotid plaques could have a worse cardiovascular prognosis, which is supported by the fact that unlike hCIMT, carotid plaque presence represents predominantly intimal thickening with foam cells, smooth muscle cells, macrophages, lipid core, and fibrous cap, depending on the stage of plaque development ${ }^{32}$.

In addition to the different pathophysiology that underlies the development of CIMT and CAP, carotid plaques seem to be more strongly determined by common CHD risk factors, such as age, sex, smoking, adiposity, hypercholesterolemia, hypertension, or diabetes ${ }^{33}$. In the present study, most of the patients were not currently smokers (88.3\%) and were under pharmacological treatment (>90\%). Nevertheless, we cannot rule out the possibility of a history of smoking exposure or low compliance with drugs therapy, which could mask the increases in CHD and lead patients to different clinical profiles, as shown in table 1 . In spite of this, multivariate logistic analysis showed that T2DM accounts for $57 \%$ of the carotid plaque presence, independently of cardiovascular risk factors, CHD or diabetes evolution time, and glycemic control. In contrast, a recent study showed that carotid plaques were not associated with $\mathrm{T}_{2} \mathrm{DM}^{34}$. However, compared with our sample, that study included a population 10 years older (only $10 \%$ with cardiovascular disease), with lower T2DM prevalence (11\% vs. $37.2 \%$ ) and without pharmacological treatment. Our findings are in agreement with those of Spagnoli et al. ${ }^{35}$, who reported that, in 180 subjects ( $62.6 \pm 7.4$ years of age) with transient CHD, age and diabetes were correlated with carotid fibrous plaques. The authors highlighted the fact that atherosclerotic plaques of diabetes patients were very rich in collagen fibers and suggest that this may be influenced by inflammation factors. This is supported by more recent findings, which indicate that the pathophysiology of
T2DM is characterized by increases in oxidative stress, soluble advanced glycation end products, and lipid peroxidation products. The latter are key activators of upstream kinases that lead to endothelial dysfunction and expression of inflammatory genes ${ }^{15}$. This information encourages our hypothesis that premature CHD patients with diabetes and carotid plaques have an increased risk of recurrent cardiovascular events and may be supported by previous data, showing that CHD-symptomatic individuals had carotid plaques with a thin fibrous cap infiltrated by macrophages and $T$ cells expressing human leukocyte antigen-DR ${ }^{36}$.

This study has several strengths. First, the number of well-characterized subjects allowed us to analyze the relationship between T2DM and the presence of CAP, adjusted by traditional and emergent cardiovascular risk factors. In addition, the fact that a single-trained specialist sonographer performed all carotid measurements ensured minimum intraobserver variability. A limitation of our study is that findings may not be fully representative of the entire CHD population due to the specific selection bias. However, patients with premature established CHD are a top-priority group for prevention in the clinical practice because they are at increased risk of total and cardiovascular disease mortality ${ }^{26,27}$. Second, the hCIMT definition applied in this report differs from other studies and could explain some differences in differences in hCIMT prevalence. Although other definitions include a CIMT, i.e., > 1 standard deviation from the mean, CIMT at the upper quartile or tertile, or absolute CIMT values $\geq 0.9$ or $\geq 1 \mathrm{~mm}$, the American Society of Echocardiography consensus statement recommends the use of CIMT greater than the $75^{\text {th }}$ percentile specific for age, ethnicity, and sex as being abnormal ${ }^{25}$. Third, the association found in the current study should be interpreted with caution, and causality cannot be determined due to the crosssectional nature of the study design. Follow-up studies are needed to analyze the real contribution of T2DM on plaque's incidence as well as the longterm impact of CIMT and carotid plaques on morbidity and mortality of patients with premature CHD. Finally, no information was collected on compliance with drug therapy, which may lead to an underestimation of the drug effects on T2DM and carotid plaque association. However, we could 
adjust for CHD and diabetes clinical evolution, as well as biochemical parameters, which are metabolic markers of disease status.

In conclusion, although the prevalence of hCIMT was higher than that of CAP, the latter was strongly and independently associated with T2DM in this studied cohort of patients with established premature CHD. Given that carotid and coronary arteries are common involved sites of atherosclerosis, the identification of carotid plaques with a noninvasive, sensitive, and reproducible method, such as B-mode ultrasound, could be useful to evaluate the risk of recurrent cardiovascular events, reduce their prevalence, and improve the prognosis among young CHD patients with T2DM.

\section{ACKNOWLEDGMENTS}

This study was supported by the Consejo Nacional de Ciencia y Tecnología (CONACyT), Mexico, project no. SALUD-2010-2-150537.

\section{REFERENCES}

1. Naghavi M, Libby P, Falk E, Casscells SW, Litovsky S, Rumberger J, et al. From vulnerable plaque to vulnerable patient. A call for new definitions and risk assessment strategies: Part II. Circulation 2003; 108:1772-8.

2. Tuzcu EM, Schoenhagen P. Acute coronary syndromes, plaque vulnerability, and carotid artery disease: the changing role of atherosclerosis imaging. J Am Coll Cardiol 2003;42:1033-6.

3. Yoko I, Naoto K, Hideaki K, Ryuichi K, Satoru S, Keita Y, et al. Maximum carotid intima-media thickness improves the prediction ability of coronary artery stenosis in type 2 diabetic patients without history of coronary artery disease. Atherosclerosis 2012;221:438-44.

4. Polak JF, Szklo M, Kronmal RA, Burke GL, Shea S, Zavodni AE, et al. The value of carotid artery plaque and intima-media thickness for incident cardiovascular disease: the multi-ethnic study of atherosclerosis. J Am Heart Assoc 2013;2:e000087.

5. Cheng LJ, Xu ZR, Zhang Q, Wang ZD, Wu FW, Yang WX. Effects of comprehensive intensive therapies on the change of intimamedia thickness of carotid arteries in type 2 diabetic patients: A report of 4-year follow-up with a literature review. Diab Vasc Dis Res 2016;13:31-40.

6. Simon A, Megnien JL, Chironi G. The value of carotid intimamedia thickness for predicting cardiovascular risk. Arterioscler Thromb Vasc Biol 2010;30:182-5.

7. Inaba Y, Chen JA, Bergmann SR. Carotid plaque, compared with carotid intima-media thickness, more accurately predicts coronary artery disease events: a meta-analysis. Atherosclerosis 2012;220:128-33.

8. Petersen C, Pecanha PB, Venneri L, Pasanisi E, Pratali L, Picano $E$. The impact of carotid plaque presence and morphology on mortality outcome in cardiological patients. Cardiovasc Ultrasound 2006;4:16

9. Chambless LE, Heiss G, Folsom AR, Rosamond W, Szklo M, Sharrett $A R$, et al. Association of coronary heart disease incidence with carotid arterial wall thickness and major risk factors: the
Atherosclerosis Risk in Communities (ARIC) Study, 1987-1993. Am J Epidemiol 1997;146:483-94.

10. Park HW, Kim WH, Kim KH, Yang DJ, Kim JH, Song IG, et al. Carotid plaque is associated with increased cardiac mortality in patients with coronary artery disease. Int J Cardiol 2013: 166:658-63.

11. Yang W, Lu J, Weng J, Jia W, Ji L, Xiao J, et al. Prevalence of diabetes among men and women in China. N Engl J Med 2010; 362:1090-1101.

12. Shaw JE, Sicree RA, Zimmet PZ. Global estimates of the prevalence of diabetes for 2010 and 2030. Diabetes Res Clin Pract 2010;87:4-14

13. Mobashir M, Varshney D, Gupta S. Cardiovascular risk factors in Type 2 diabetes mellitus [abstract]. Medicine Update 2005; 254-62.

14. Achari V, Thakur AK, Sinha AK. The metabolic syndrome-its prevalence and association with coronary artery disease in type 2 diabetes. JIACM 2006; 7:32-8

15. Simon AS, Vijayakumar T. Molecular studies on coronary artery disease-a review. Indian J Clin Biochem 2013;28:215-26.

16. Akazawa S, Tojikubo M, Nakano Y, Nakamura S, Kawasaki T, Koga N. Usefulness of sum of the thickness of plaque in the carotid artery for predicting the presence and the extent of the coronary artery disease in patients with type 2 diabetes mellitus without known coronary artery disease. Diabetes Res Clin Pract 2012;96:111-8

17. Irie $Y$, Katakami N, Kaneto H, Kasami R, Sumitsuji S, Yamasaki $\mathrm{K}$, et al. Maximum carotid intima-media thickness improves the prediction ability of coronary artery stenosis in type 2 diabetic patients without history of coronary artery disease. Atherosclerosis 2012:221:438-44

18. Villarreal-Molina T, Posadas-Romero C, Romero-Hidalgo S, Antúnez-Argüelles E, Bautista-Grande A, Vargas-Alarcón G, et al. The ABCA1 gene R230C variant is associated with decreased risk of premature coronary artery disease: the genetics of atherosclerotic disease (GEA) study. PLoS One 2012; 7:e49285.

19. Zhan C, Shi M, Yang Y, Pang H, Fei S, Bai L, et al. Prevalence and risk factors of carotid plaque among middle-aged and elderly adults in rural Tianjin, China. Sci Rep 2016;6:23870.

20. Baecke JA, Burema J, Frijters JE. A short questionnaire for the measurement of habitual physical activity in epidemiological studies. Am J Clin Nutr 1982;36:936-42.

21. De Long DM, De Long ER, Wood PD, Lippel K, Rifkind BM. A comparison of methods for the estimation of plasma low- and very low-density lipoprotein cholesterol. The Lipid Research Clinics Prevalence Study. JAMA 1986;256:2372-7.

22. American Diabetes Association. Glycemic Targets. Diabetes Care 2016:39 Suppl 1:S39-46.

23. Maurovich-Horvat P, Massaro J, Fox CS, MoselewskiF, O'Donnell C], Hoffmann U. Comparison of anthropometric, area- and volume-based assessment of abdominal subcutaneous and visceral adipose tissue volumes using multi-detector computed tomography. Int J Obes 2007;31:500-6.

24. Kvist H, Chowdhury B, Grangård U, Tylén U, Sjöström L. Total and visceral adipose-tissue volumes derived from measurements with computed tomography in adult men and women: predictive equations. Am J Clin Nutr 1988;48:1351-61.

25. Stein JH, Korcarz CE, Hurst RT, Lonn E, Kendall CB, Mohler ER et al. American Society of Echocardiography Carotid IntimaMedia Thickness Task Force: Use of carotid ultrasound to identify subclinical vascular disease and evaluate cardiovascular disease risk: a consensus statement from the American Society of Echocardiography Carotid Intima-Media Thickness Task Force. Endorsed by the Society for Vascular Medicine. J Am Soc Echocardiogr 2008;21:93-111.

26. Chambless L, Keil U, Dobson A, Mähönen M, Kuulasmaa K Rajakangas AM, et al. Population versus clinical view of case fatality from acute coronary heart disease: results from the WHO MONICA Project 1985-1990. Multinational MONItoring of Trends and Determinants in Cardiovascular Disease. Circulation 1997;96:3849-59.

27. European Guidelines on Cardiovascular Disease Prevention in Clinical Practice. Fourth Joint European Societies' Task Force on Cardiovascular Disease Prevention in Clinical Practice. Eur J Cardiovasc Prev Rehabil 2007;14:S1-113.

28. Limbu YR, Rajbhandari R, Sharma R, Singh S, Limbu D, Adhikar CM, et al. Carotid intima-media thickness (CIMT) and carotid plaques in young Nepalese patients with angiographically documented coronary artery disease. Cardiovasc Diagn Ther 2015; 5:1-7 
29. Allzadehasl A, Sepasi F, Toutan M. Risk factors, clinical manifestations and outcome of acute myocardial infarction in young patients. J Cardiovasc Thorac Res 2010;2:29-34

30. Ashif M. Role of fruit, vegetables and spice in diabetes. Int J Nutr Pharm Neurol Dis 2011;1:27-35.

31. Bots ML, Evans GW, Riley WA, Grobbee DE. Carotid intimamedia thickness measurements in intervention studies: design options, progression rates, and sample size considerations: a point of view. Stroke 2003;34:2985.

32. Nicolaides AN. Ultrasound and Carotid Bifurcation Atherosclerosis. New York: Springer, 2011.

33. Moskau S, Golla A, Grothe C, Boes M, Pohl C, Klockgether T. Heritability of carotid artery atherosclerotic lesions: an ultrasound study in 154 families. Stroke 2005;36:5-8.
34. Ihle-Hansen $H$, Vigen $T$, Ihle-Hansen $H$, Ronning OM, Berge $T$, Thommessen B, et al. Prevalence of carotid plaque in a 63- to 65-Year-Old Norwegian cohort from the general population: The ACE (Akershus Cardiac Examination) 1950 Study. J Am Heart Assoc 2018; 7: e008562.

35. Spagnoli LG, Mauriello A, Palmieri G, Santeusanio G, Amante A, Taurino M. Relationships between risk factors and morphological patterns of human carotid atherosclerotic plaques. A multivariate discriminant analysis. Atherosclerosis 1994; 108:39-60.

36. Yahagi K, Kolodgie FD, Lutter C, Mori H, Romero ME, Finn AV, et al. Pathology of human coronary and carotid artery atherosclerosis and vascular calcification in diabetes mellitus. Arterioscler Thromb Vasc Biol 2017;37:191-204. 